\title{
Mathematical model to calculate the critical value of the angle of gradient for a tractor- mounted tilther
}

\author{
Anatolii Kudzaev ${ }^{*}, 1$, Alan Tsgoev ${ }^{1}$, Ivan Korobeynik ${ }^{1}$, Rita Kalagova ${ }^{2}$, and Taimuraz \\ Urtaev $^{1}$ \\ ${ }^{1}$ Gorsky State Agrarian University, 362040, 37, Kirova str., Vladikavkaz, Republic of North Ossetia- \\ Alania, Russia \\ ${ }^{2}$ State Budgetary Educational Institution of Higher Professional Education "North-Caucasus State \\ Medical Academy". Vladikavkaz, Republic of North Ossetia-Alania, Russia
}

\begin{abstract}
The article is devoted to the search for a mathematical model convenient for practical calculations to determine the critical value of the angle of gradient for the tractor-mounted heavy tilther. It shows the existing mathematical model, which is then refined based on the stiffness of the elastic tractor wheels and their vertical reactions offset. Three methods of solving the resulting equations are analyzed, upon which the optimal one is chosen. As a result, a simple and convenient in practice mathematical model to determine the critical value of the angle of gradient for the tractor-mounted implement is obtained. The analysis of the calculation results showed that depending on the operating conditions and the weight of the tractor counterweight, the differences between the results calculated using the traditional and refined models can reach more than 4 degrees, which is very important to ensure the hill climbing safety.
\end{abstract}

\section{Introduction}

Despite the great success in the development of agricultural machines, the safety problem of their operation in difficult terrain is very acute. In 53 countries, mountain areas cover more than $50 \%$ of the country's territory [1]. Injuries when using tractors in agriculture are very high, especially when cultivating fields located in the mountain area, it is not infrequent for machines overturn, which often result in fatalities [2-3]. A number of scientists consider the need to equip agricultural machines with various safety devices as one of the ways to reduce injuries in agriculture [4]. In relation to tilthers, they are described in [5-9]. However, many scientists prefer to improve the design of the tractor itself, designed to operate in difficult conditions [10-12].

Various mathematical models to analyze the agricultural tractors stability, which ultimately allows obtaining more integrated picture of various factors impact on the machine stability are of great interest [13-15]. However, to perform practical calculations, it

\footnotetext{
*Corresponding author : akudzaev@rambler.ru
} 
is very important to have a simple mathematical model that provides a sufficient accuracy level.

Hence, we have attempted to refine the existing mathematical models to analyze the longitudinal stability of the tractor unit operating under various conditions.

\section{Materials and methods}

To conduct research, we applied a theoretical method by deriving balance equations for the tractor-mounted tilther travelling up a slope. Due to the low speeds of the tractor unit, it has been decided not to consider its inertia and air flow resistance forces.

The research program is quite simple. First, give the formula to calculate the critical value of the unit angle of gradient, which is usually used for practical calculations. At the second stage, refine the balance equations by considering the horizontal offset of vertical reactions from the vertical axis of symmetry of wheels. Solve the resulting equations in various ways. At the third stage, it was necessary to compare the calculation results obtained from the traditional and refined models, evaluate the results significance for practice. It was also necessary to evaluate the acceptability for practical calculations of various simplifications made when solving refined equations.

The real parameters of a reversible plough have been adopted as a tractor-mounted machine since the travel of this machine, which has a large mass and size cause great difficulties in mountain areas.

\section{Mathematical models to calculate the critical value of the unit angle of gradient}

\section{Traditional model}

The figure shows the design diagram to determine the critical value of the angle of gradient $\alpha$ for the tractor unit:

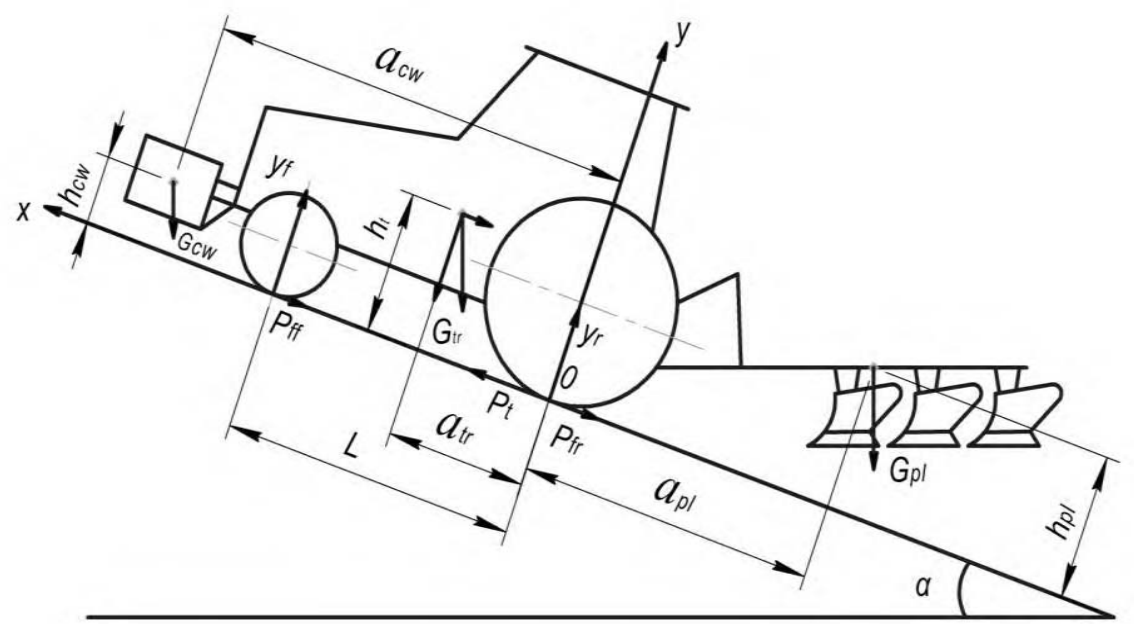

Fig. 1. Diagram of forces acting on the tractor with a plough travelling up a slope

Let us derive balance equations for the tractor unit: 


$$
\begin{gathered}
\sum \mathrm{X}=0 ;-G_{p l} \sin \alpha-P_{f r}-G_{t r} \sin \alpha-P_{f f}-G_{c w} \sin \alpha+P_{t}=0, \\
\sum Y=0 ;-G_{p l} \cos \alpha+\mathrm{y}_{r}-G_{t r} \cos \alpha+\mathrm{y}_{f}-G_{c w} \cos \alpha=0, \\
\sum M_{o}=0 ; G_{p l} \cos \alpha \cdot a_{p l}+G_{p l} \sin \alpha h_{p l}-G_{t r} \cos \alpha \cdot a_{t r}+G_{t r} \sin \alpha \cdot h_{t r}+Y_{f} \cdot L- \\
G_{c w} \cos \alpha \cdot a_{c w}+G_{c w} \sin \alpha \cdot h_{c w}=0,
\end{gathered}
$$

where $G_{t r}, G_{p l}, G_{c w}$ are the weight of the tractor, plough, counterweight, (N);

$\mathrm{P}_{\mathrm{t}}$ is a tangential tractive force, $(\mathrm{N})$;

$\mathrm{y}_{\mathrm{f}}, \mathrm{y}_{\mathrm{r}}$ are the front and rear wheels reaction, $(\mathrm{N})$;

$\alpha$ is an angle of gradient, (rad);

$\mathrm{L}$ is a tractor base, $(\mathrm{m})$

$\alpha_{\mathrm{t}}, \alpha_{\mathrm{pl}}, \alpha_{\mathrm{cw}}$ are horizontal coordinates of the center of gravity of the tractor, plough, counterweight, (m).

$\mathrm{h}_{\mathrm{t}}, \mathrm{h}_{\mathrm{pl}}, \mathrm{h}_{\mathrm{cw}}$ are vertical coordinates of the center of gravity of the tractor, plough, counterweight, $(\mathrm{m})$;

$\mathrm{P}_{\mathrm{ff}}, \mathrm{P}_{\mathrm{fr}}$ are the rolling resistance force of the front and rear wheels, $(\mathrm{N})$.

From equation (2) we can deduce that

$$
\mathrm{y}_{r}=G_{p l} \cos \alpha+G_{t r} \cos \alpha+G_{c w} \cos \alpha-\mathrm{y}_{f}
$$

or having symbolized by $\mathrm{G}_{\mathrm{s}}$ the weighted sum of the tractor, plough and counterweight:

$$
G_{s}=G_{p l}+G_{t r}+G_{c w}
$$

derive:

$$
\mathrm{y}_{r}=G_{s} \cdot \cos \alpha-\mathrm{y}_{f}
$$

The value of the vertical reaction $\mathrm{Y}_{\mathrm{f}}$ can be determined from equation (3):

$$
\begin{aligned}
\mathrm{y}_{f}= & \frac{1}{L} \cdot\left\{\left(G_{t r} \cdot a_{t r}+G_{c w} \cdot a_{c w}-G_{p l} a_{p l}\right) \cdot \cos \alpha-\right. \\
& \left.-\left(G_{p l} \cdot h_{p l}+G_{t r} \cdot h_{t r}++G_{c w} h_{c w}\right) \cdot \sin \alpha\right\} .
\end{aligned}
$$

In order to determine the critical value of the angle of gradient $\alpha_{\mathrm{cv}}$ it is necessary to put value $\mathrm{y}_{\mathrm{f}}=0$ in equation (5), then

$$
\alpha_{c v}=\operatorname{arctg}\left[\frac{G_{t r} \cdot a_{t r}+G_{c w} \cdot a_{c w}-G_{p l} \cdot a_{p l}}{G_{p l} \cdot h_{p l}+G_{t r} \cdot h_{t r}+G_{c w} \cdot h_{c w}}\right] .
$$

Formula (6) allows calculating the critical value of the angle of gradient that the plowing unit in the transit condition can overcome. These formulas are acceptable to calculate at high values of tires pressure and driving on paved roads. Now let us derive these formulas considering the real wheels reaction points (the case of travelling the elastic wheeled tractor on soft ground).

1.2 Refined model

The design diagram is shown in figure 2. Accordingly, the balance equations for this case will be:

$$
\begin{gathered}
\sum \mathrm{x}=0 . \quad G_{p l} \cdot \sin \alpha-P_{f r}-P_{j}-P_{f f}-G_{c w} \sin \alpha+P_{t}=0 ; \\
\sum \mathrm{y}=0 . \quad-G_{p l} \cos \alpha+\mathrm{y}_{r}-G_{t r} \cos \alpha+\mathrm{y}_{f}-G_{c w} \cos \alpha=0
\end{gathered}
$$




$$
\begin{aligned}
& \sum M_{0}=0 . \quad G_{p l} \cos \alpha \cdot a_{p l}+G_{p l} \sin \alpha \cdot h_{p l}-G_{t r} \cos \alpha \cdot a_{t r}+G_{t r} \sin \alpha \cdot h_{t r}+ \\
& +\mathrm{y}_{f}\left(L_{1}+a_{f}\right)-G_{c w} \cos \alpha \cdot a_{c w}+G_{c w} \sin \alpha \cdot h_{c w}+\mathrm{y}_{r} \cdot a_{r}+P_{j} \cdot h_{t r}=0 .
\end{aligned}
$$

The value for $\mathrm{Y}_{\mathrm{f}}$ can be determined from equation (9):

$$
\begin{aligned}
\mathrm{y}_{\mathrm{f}}= & \frac{1}{\mathrm{~L}+\mathrm{a}_{\mathrm{f}}} \cdot\left(\mathrm{G}_{\mathrm{cw}} \cdot \cos \alpha \cdot \mathrm{a}_{\mathrm{cw}}+\mathrm{G}_{\mathrm{tr}} \cdot \cos \alpha \cdot \mathrm{a}_{\mathrm{tr}}-\mathrm{G}_{\mathrm{pl}} \cdot \cos \alpha \cdot \mathrm{a}_{\mathrm{pl}}-\mathrm{G}_{\mathrm{pl}} \cdot \sin \alpha \cdot\right. \\
& \left.\mathrm{h}_{\mathrm{pl}}-\mathrm{G}_{\mathrm{tr}} \cdot \sin \alpha \cdot \mathrm{h}_{\mathrm{tr}}-\mathrm{G}_{\mathrm{cw}} \cdot \sin \alpha \cdot \mathrm{h}_{\mathrm{tr}}-\mathrm{P}_{\mathrm{j}} \mathrm{h}_{\mathrm{tr}}\right)-\frac{\mathrm{y}_{\mathrm{r}} \cdot \mathrm{a}_{r}}{L+\mathrm{a}_{f}}
\end{aligned}
$$

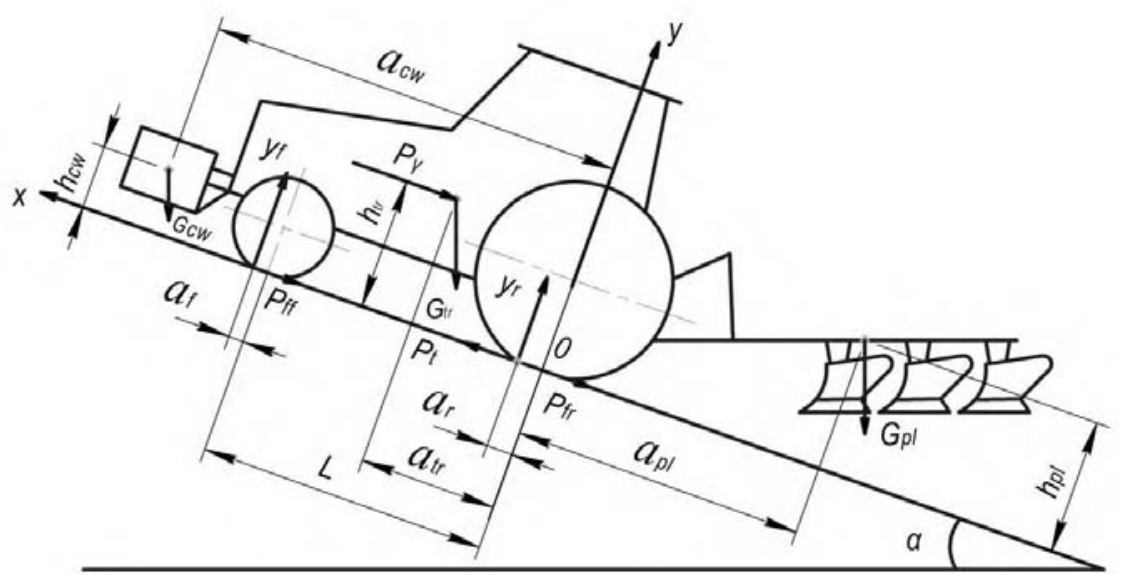

Fig. 2. Design diagram of the tractor with a plough travelling up a slope, based on the real application of front and rear wheels reaction

Let us substitute the formula for $\mathrm{y}_{\mathrm{r}}$ from equality (4) to the last equation, then

$$
\begin{aligned}
& \mathrm{y}_{f}=\frac{1}{L+\mathrm{a}_{f}} \cdot\left(G_{c w} \cdot \cos \alpha \cdot a_{c w}+G_{t r} \cdot \cos \alpha \cdot a_{t r}-G_{p l} \cdot \cos \alpha \cdot a_{p l}-G_{p l} \cdot \sin \alpha \cdot\right. \\
& \left.h_{p l}-G_{t r} \cdot \sin \alpha \cdot h_{t r}-G_{c w} \cdot \sin \alpha \cdot h_{c w}-P_{j} h_{t r}-G_{s} \cdot \cos \alpha \cdot a_{r}\right)+\mathrm{y}_{f} \cdot \frac{a_{r}}{L+a_{f}},
\end{aligned}
$$

wherefrom the formula to determine $\mathrm{y}_{\mathrm{f}}$ will be:

$$
\begin{aligned}
& \mathrm{y}_{f}=\frac{1}{\left(L+a_{f}\right) \cdot\left(1-\frac{a_{r}}{L+a_{f}}\right)} \cdot\left[G_{c w} \cdot\left(\mathrm{a}_{c w} \cdot \cos \alpha-h_{c w} \sin \alpha\right)+G_{c w}\left(\mathrm{a}_{t r} \cdot \cos \alpha--h_{t r} \sin \alpha\right)-\right. \\
& \left.G_{p l} \cdot\left(\mathrm{a}_{p l} \cdot \cos \alpha-h_{p l} \sin \alpha\right)-P_{j} h_{t r}-G_{s} a_{r} \cdot \cos \alpha\right] .
\end{aligned}
$$

Hence, from this equation, we can derive the formula to calculate the maximum value of the angle of gradient for the tractor unit by putting $\mathrm{Y}_{\mathrm{f}}=0$ in equation (10). That is, the angle $\alpha_{\mathrm{cv}}$ will be:

$$
\alpha_{c v}=\operatorname{arctg}\left[\frac{G_{c w} \cdot a_{c w}+G_{\mathrm{tr}} \cdot a_{\mathrm{tr}}-G_{p l} \cdot a_{p l}-G_{s} \cdot a_{r}}{G_{p l} \cdot h_{p l}+G_{t r} \cdot h_{\mathrm{tr}}+G_{c w} \cdot h_{c w}}\right]
$$


Equation (11) is more exact than equation (6). Unlike equation (6), the numerator contains the product $G_{s} \cdot \alpha_{r}$, which makes a relevant correction for estimating the critical value of the angle of gradient.

However, to use equation (11), it is necessary to know the value for $\alpha_{\mathrm{r}}$. To do this, let us use the known dependencies that describe the relationship between the rolling resistance coefficient and the dynamic rolling radius $\mathrm{rd}$ :

$$
f=\frac{a}{r_{d}}
$$

where, $\alpha$ is the vertical reaction offset $\mathrm{Y}$ from the vertical axis of symmetry of the wheel; $r_{d}$ is a dynamic rolling radius of the wheel.

Accordingly, the dependence (12) for the front and rear wheels will be:

$$
\begin{gathered}
f_{f}=\frac{a_{f}}{r_{d f}}, \\
f_{r}=\frac{a_{r}}{r_{d r}},
\end{gathered}
$$

where, $r_{d f}, r_{d r}$ are dynamic radii for the front and rear wheels.

Then, the formulas for $\alpha_{\mathrm{f}}$ and $\alpha_{\mathrm{r}}$, based on the tires stiffness will be:

$$
\begin{gathered}
a_{f}=f_{f} \cdot r_{d f}=f_{f}\left(r_{s f}-\frac{\mathrm{y}_{f}}{\mathrm{c}_{t f}}\right), \\
a_{r}=f_{r} \cdot r_{d r}=f_{r}\left(r_{s r}-\frac{\mathrm{y}_{r}}{\mathrm{c}_{t r}}\right),
\end{gathered}
$$

where, $r_{\mathrm{sf}}, \mathrm{r}_{\mathrm{sr}}$ are static radii for the front and rear wheels $(\mathrm{m})$;

$\mathrm{C}_{t f}, \mathrm{C}_{t r}$ are the of radial stiffness coefficients for front and rear wheels, $(\mathrm{N} / \mathrm{m})$.

Having substituted the value for $\mathrm{y}_{\mathrm{r}}$ reaction from formula (4) to formula (16), we obtain:

$$
a_{r}=f_{r} r_{s r}-\frac{f_{r}}{C_{t r}} G_{s} \cos \alpha-\frac{f_{r} \cdot \mathrm{y}_{f}}{C_{t r}}
$$

To determine the critical value of the angle $\alpha_{\mathrm{cv}}$, let us equate the formula (10) to zero and substitute the formula for $\alpha_{r}$ from (17) to it. Then, by putting $\mathrm{Y}_{\mathrm{f}}=0, \mathrm{P}_{\mathrm{j}}=0$ the formula can be written as follows:

$$
\begin{aligned}
\left(G_{c w} \cdot a_{c w}\right. & \left.+G_{t r} \cdot a_{t r}-G_{p l} \cdot a_{p l}\right) \cdot \cos \alpha-G_{s} f_{r} r_{s r}-\cos \alpha+\frac{f_{r}}{C_{t r}} G_{c}^{2} \cdot \cos ^{2} \alpha= \\
& =\left(G_{c w} \cdot h_{c w}+G_{t r} \cdot h_{t r}+G_{p l} \cdot h_{p l}\right) \cdot \sin \alpha .
\end{aligned}
$$

The most rational solution of equation (18) is numerical, which can be easily implemented with the given accuracy.

In practice, it is not always convenient to use the numerical solution method, so let us try to deduce the acceptable formulas. To do this, pay attention to formula (16). Since the $\mathrm{C}_{\mathrm{tr}}$ value is very large, then

$$
\left(\mathrm{Y}_{\mathrm{r}} / \mathrm{C}_{\mathrm{tr}}\right) \approx\left(\mathrm{G}_{\mathrm{s}} / \mathrm{C}_{\mathrm{tr}}\right)
$$

Considering (19) and (16), formula (11) can be written as follows: 


$$
\alpha_{c v}=\operatorname{arctg}\left[\frac{G_{c w} \cdot a_{c w}+G_{t r} \cdot a_{t r}-G_{p l} \cdot a_{p l}-G_{s} \cdot\left(f_{r} \cdot\left(r_{s r}-\frac{G_{s}}{C_{t r}}\right)\right)}{G_{p l} \cdot h_{p l}+G_{t r} \cdot h_{t r}+G_{c w} \cdot h_{c w}}\right] .
$$

Thus, we have three models to analyze: formula (6) (method 1), equation (18) which is solved numerically (method 2), and formula (20) (method 3).

\section{Results}

To perform calculations, let us use the parameters of MTZ-80 tractor with reversible plough PON-3M. Let us also assume that the wheel tire stiffness varies from $18 \mathrm{kN} / \mathrm{m}$ to $30 \mathrm{kN} / \mathrm{m}$, the weight of counterweight - from $0 \mathrm{kN}$ to $5 \mathrm{kN}$, and the rolling resistance coefficient from 0.025 to 0.1 .

The calculation results are shown in the table. 
Table 1. The calculation results of the critical values of the angle of gradient for the tractor with the reversible plough weighing $1070 \mathrm{~kg}$ performed by various calculation methods when travelling the tractor unit on roads with surfaces of different type, the weight of counterweight and tire stiffness.

\begin{tabular}{|c|c|c|c|c|c|c|c|c|}
\hline \multirow{2}{*}{ № } & \multirow{2}{*}{$\begin{array}{l}\text { rolling resistance } \\
\text { coefficient } \\
\text { f }\end{array}$} & \multirow[b]{2}{*}{$\begin{array}{l}\text { tires stiffness } \\
\mathrm{Ct}, \mathbf{N} / \mathbf{m}\end{array}$} & \multirow{2}{*}{$\begin{array}{c}\text { weight of } \\
\text { counterweight } \\
\text { Gcw, N }\end{array}$} & \multicolumn{3}{|c|}{ Calculation methods } & \multicolumn{2}{|c|}{ Error } \\
\hline & & & & $\begin{array}{c}\text { method1, } \\
\text { Traditio } \\
\text { nal }\end{array}$ & $\begin{array}{l}\text { method } \\
2, \\
\text { Refined }\end{array}$ & $\begin{array}{c}\text { method } 3 \\
\text { Approxima } \\
\text { te }\end{array}$ & $\begin{array}{c}\text { method } \\
1 \\
\text { p1, } \%\end{array}$ & $\begin{array}{c}\text { meth } \\
\text { od 3 } \\
\text { p2, } \\
\%\end{array}$ \\
\hline $\mathbf{0}$ & 1 & 2 & 3 & 4 & 5 & 6 & 7 & 8 \\
\hline 1 & 0,025 & 180000 & $\mathbf{0}$ & 5,2998 & 4,3717 & 4,368 & 17,5 & 0,08 \\
\hline 2 & 0,025 & 180000 & 1000 & 8,5528 & 7,6318 & 7,634 & 10,8 & $-0,03$ \\
\hline 3 & 0,025 & 180000 & 2000 & 11,667 & 10,766 & 10,77 & 7,73 & $-0,01$ \\
\hline 4 & 0,025 & 180000 & 3000 & 14,635 & 13,751 & 13,76 & 6,04 & $-0,04$ \\
\hline 5 & 0,025 & 180000 & 4000 & 17,451 & 16,587 & 16,6 & 4,95 & $-0,07$ \\
\hline 6 & 0,025 & 180000 & 5000 & 20,114 & 19,274 & 19,29 & 4,17 & $-0,08$ \\
\hline 7 & 0,025 & 220000 & $\mathbf{0}$ & 5,2998 & 4,3029 & 4,303 & 18,8 & 0 \\
\hline 8 & 0,025 & 220000 & 1000 & 8,5528 & 7,5688 & 7,568 & 11,5 & 0,01 \\
\hline 9 & 0,025 & 220000 & 2000 & 11,667 & 10,697 & 10,7 & 8,32 & $-0,03$ \\
\hline 10 & 0,025 & 220000 & 3000 & 14,635 & 13,682 & 13,69 & 6,51 & $-0,05$ \\
\hline 11 & 0,025 & 220000 & 4000 & 17,451 & 16,524 & 16,53 & 5,31 & $-0,04$ \\
\hline 12 & 0,025 & 220000 & 5000 & 20,114 & 19,211 & 19,22 & 4,49 & $-0,06$ \\
\hline 13 & 0,025 & 260000 & 0 & 5,2998 & 4,2571 & 4,258 & 19,7 & $-0,01$ \\
\hline 14 & 0,025 & 260000 & 1000 & 8,5528 & 7,5229 & 7,522 & 12 & 0,02 \\
\hline 15 & 0,025 & 260000 & 2000 & 11,667 & 10,651 & 10,65 & 8,71 & $-0,02$ \\
\hline 16 & 0,025 & 260000 & 3000 & 14,635 & 13,636 & 13,64 & 6,82 & $-0,05$ \\
\hline 17 & 0,025 & 260000 & 4000 & 17,451 & 16,478 & 16,48 & 5,57 & $-0,04$ \\
\hline 18 & 0,025 & 260000 & 5000 & 20,114 & 19,165 & 19,18 & 4,72 & $-0,06$ \\
\hline 19 & 0,025 & 300000 & 0 & 5,2998 & 4,2284 & 4,224 & 20,2 & 0,1 \\
\hline 20 & 0,025 & 300000 & 1000 & 8,5528 & 7,4886 & 7,488 & 12,4 & 0,01 \\
\hline 21 & 0,025 & 300000 & 2000 & 11,667 & 10,617 & 10,62 & 9 & $-0,02$ \\
\hline 22 & 0,025 & 300000 & 3000 & 14,635 & 13,608 & 13,61 & 7,02 & $-0,01$ \\
\hline 23 & 0,025 & 300000 & 4000 & 17,451 & 16,444 & 16,45 & 5,77 & $-0,04$ \\
\hline 24 & 0,025 & 300000 & 5000 & 20,114 & 19,131 & 19,14 & 4,89 & $-0,06$ \\
\hline 25 & 0,06 & 180000 & 0 & 5,2998 & 3,0596 & 3,061 & 42,3 & $-0,03$ \\
\hline 26 & 0,06 & 180000 & 1000 & 8,5528 & 6,3369 & 6,342 & 25,9 & $-0,08$ \\
\hline 27 & 0,06 & 180000 & 2000 & 11,667 & 9,4882 & 9,497 & 18,7 & $-0,1$ \\
\hline 28 & 0,06 & 180000 & 3000 & 14,635 & 12,496 & 12,52 & 14,6 & $-0,16$ \\
\hline 29 & 0,06 & 180000 & 4000 & 17,451 & 15,361 & 15,39 & 12 & $-0,2$ \\
\hline 30 & 0,06 & 180000 & 5000 & 20,114 & 18,077 & 18,12 & 10,1 & $-0,24$ \\
\hline 31 & 0,06 & 220000 & 0 & 5,2998 & 2,9049 & 2,903 & 45,2 & 0,07 \\
\hline 32 & 0,06 & 220000 & 1000 & 8,5528 & 6,1822 & 6,181 & 27,7 & 0,02 \\
\hline 33 & 0,06 & 220000 & 2000 & 11,667 & 9,3278 & 9,335 & 20,1 & $-0,08$ \\
\hline 34 & 0,06 & 220000 & 3000 & 14,635 & 12,342 & 12,35 & 15,7 & $-0,09$ \\
\hline 35 & 0,06 & 220000 & 4000 & 17,451 & 15,206 & 15,23 & 12,9 & $-0,15$ \\
\hline 36 & 0,06 & 220000 & 5000 & 20,114 & 17,928 & 17,96 & 10,9 & $-0,17$ \\
\hline 37 & 0,06 & 260000 & 0 & 5,2998 & 2,796 & 2,794 & 47,2 & 0,08 \\
\hline 38 & 0,06 & 260000 & 1000 & 8,5528 & 6,0676 & 6,07 & 29,1 & $-0,04$ \\
\hline 39 & 0,06 & 260000 & 2000 & 11,667 & 9,2189 & 9,222 & 21 & $-0,04$ \\
\hline 40 & 0,06 & 260000 & 3000 & 14,635 & 12,227 & 12,24 & 16,5 & $-0,11$ \\
\hline
\end{tabular}




\begin{tabular}{|l|l|l|l|l|l|l|l|l|}
\hline 41 & 0,06 & 260000 & 4000 & $\mathbf{1 7 , 4 5 1}$ & $\mathbf{1 5 , 0 9 7}$ & $\mathbf{1 5 , 1 2}$ & 13,5 & $-0,12$ \\
\hline 42 & 0,06 & 260000 & 5000 & $\mathbf{2 0 , 1 1 4}$ & $\mathbf{1 7 , 8 1 9}$ & $\mathbf{1 7 , 8 4}$ & 11,4 & $-0,15$ \\
\hline
\end{tabular}

\begin{tabular}{|c|c|c|c|c|c|c|c|c|}
\hline 43 & 0,06 & 300000 & 0 & 5,2998 & 2,7158 & 2,714 & 48,8 & 0,08 \\
\hline 44 & 0,06 & 300000 & 1000 & 8,5528 & 5,9874 & 5,988 & 30 & $-0,02$ \\
\hline 45 & 0,06 & 300000 & 2000 & 11,667 & 9,1387 & 9,14 & 21,7 & $\begin{array}{c}-0,01 \\
\end{array}$ \\
\hline 46 & 0,06 & 300000 & 3000 & 14,635 & 12,147 & 12,16 & 17 & $-0,08$ \\
\hline 47 & 0,06 & 300000 & 4000 & 17,451 & 15,017 & 15,03 & 13,9 & $-0,1$ \\
\hline 48 & 0,06 & 300000 & 5000 & 20,114 & 17,739 & 17,76 & 11,8 & $-0,13$ \\
\hline 49 & 0,1 & 180000 & 0 & 5,2998 & 1,5642 & 1,562 & 70,5 & 0,13 \\
\hline 50 & 0,1 & 180000 & 1000 & 8,5528 & 4,853 & 4,857 & 43,3 & $-0,08$ \\
\hline 51 & 0,1 & 180000 & 2000 & 11,667 & 8,0214 & 8,035 & 31,2 & $-0,17$ \\
\hline 52 & 0,1 & 180000 & 3000 & 14,635 & 11,058 & 11,08 & 24,4 & $-0,24$ \\
\hline 53 & 0,1 & 180000 & 4000 & 17,451 & 13,957 & 14 & 20 & $-0,28$ \\
\hline 54 & 0,1 & 180000 & 5000 & 20,114 & 16,707 & 16,77 & 16,9 & $-0,35$ \\
\hline 55 & 0,1 & 220000 & 0 & 5,2998 & 1,3006 & 1,299 & 75,5 & 0,14 \\
\hline 56 & 0,1 & 220000 & 1000 & 8,5528 & 4,5894 & 4,588 & 46,3 & 0,03 \\
\hline 57 & 0,1 & 220000 & 2000 & 11,667 & 7,7521 & 7,762 & 33,6 & $-0,13$ \\
\hline 58 & 0,1 & 220000 & 3000 & 14,635 & 10,789 & 10,81 & 26,3 & $-0,19$ \\
\hline 59 & 0,1 & 220000 & 4000 & 17,451 & 13,688 & 13,72 & 21,6 & $-0,24$ \\
\hline 60 & 0,1 & 220000 & 5000 & 20,114 & 16,444 & 16,49 & 18,2 & $-0,28$ \\
\hline 61 & 0,1 & 260000 & 0 & 5,2998 & 1,1173 & 1,116 & 78,9 & 0,07 \\
\hline 62 & 0,1 & 260000 & 1000 & 8,5528 & 4,4003 & 4,402 & 48,6 & $-0,03$ \\
\hline 63 & 0,1 & 260000 & 2000 & 11,667 & 7,5688 & 7,573 & 35,1 & $-0,05$ \\
\hline 64 & 0,1 & 260000 & 3000 & 14,635 & 10,605 & 10,62 & 27,5 & $-0,12$ \\
\hline 65 & 0,1 & 260000 & 4000 & 17,451 & 13,505 & 13,53 & 22,6 & $-0,18$ \\
\hline 66 & 0,1 & 260000 & 5000 & 20,114 & 16,261 & 16,3 & 19,2 & $-0,24$ \\
\hline 67 & 0,1 & 300000 & 0 & 5,2998 & 0,9855 & 0,983 & 81,4 & 0,28 \\
\hline 68 & 0,1 & 300000 & 1000 & 8,5528 & 4,2628 & 4,265 & 50,2 & $-0,05$ \\
\hline 69 & 0,1 & 300000 & 2000 & 11,667 & 7,4313 & 7,434 & 36,3 & $-0,04$ \\
\hline 70 & 0,1 & 300000 & 3000 & 14,635 & 10,468 & 10,48 & 28,5 & $-0,1$ \\
\hline 71 & 0,1 & 300000 & 4000 & 17,451 & 13,367 & 13,39 & 23,4 & $-0,16$ \\
\hline 72 & 0,1 & 300000 & 5000 & 20,114 & 16,123 & 16,16 & 19,8 & $-0,22$ \\
\hline
\end{tabular}

The table shows that when the weight of the counterweight increases and the tractor travel along the same surface, the tire stiffness has an insignificant effect on the calculation result. The most significant factors are the rolling resistance coefficient and the weight of the counterweight.

The table also shows that the difference between the calculation results for method 1 and method 2 is quite significant, while it is insignificant between methods 2 and 3 . This is clear in the graphs shown in figures 3 and 4.

Figure 3 represents by a diagram the differences in the results of calculating the critical value of the unit angle of gradient between methods 1 and 2 (column 7 in the table).

Figure 4 represents by a diagram the differences in the results of calculating the critical value of the unit angle of gradient between methods 1 and 2, but they are already expressed in degrees. 


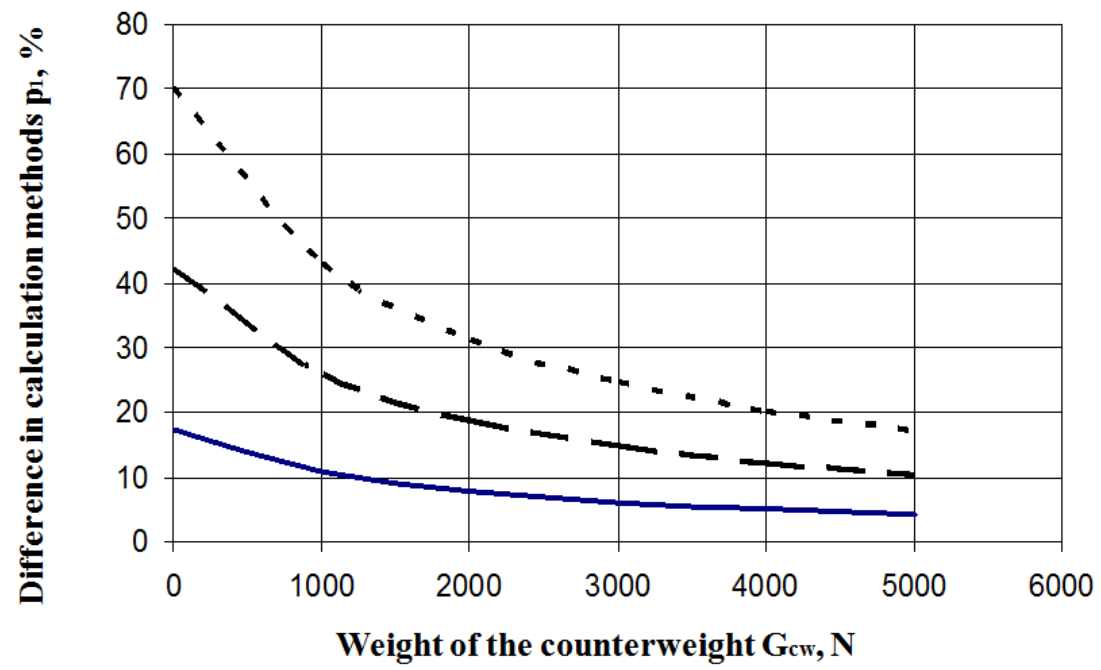

Fig. 3. Differences in the results of calculating the critical value of the angle of gradient for the tractor with the reversible plough $\mathrm{p} 1 \%$ ), obtained by the existing and proposed methods, from the weight of the counterweight with road surfaces of different type

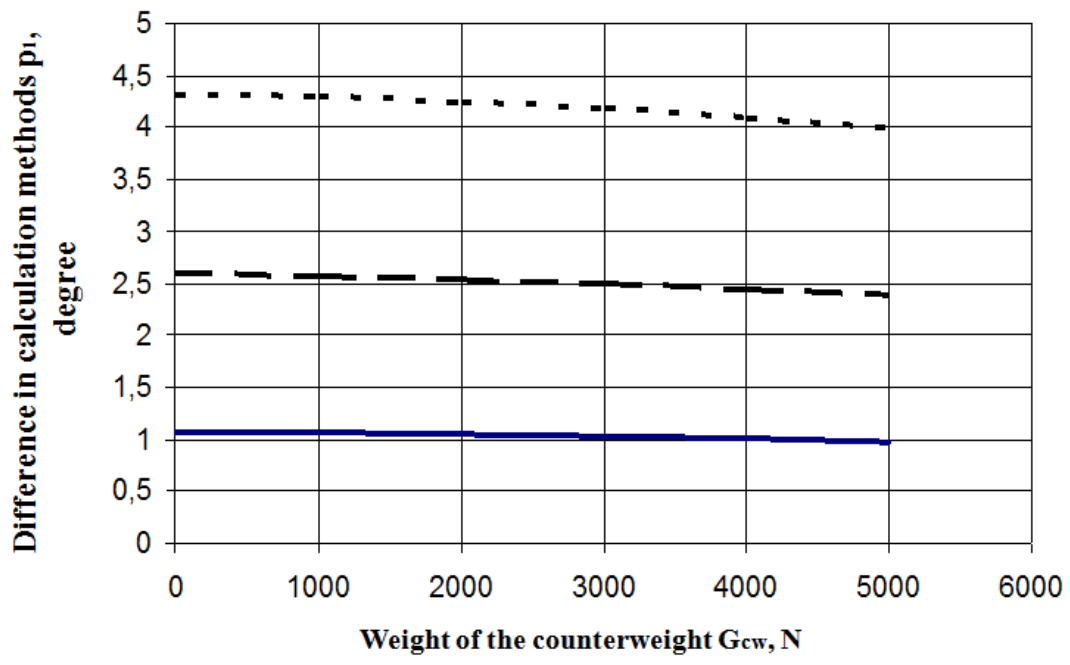

Fig. 4. Differences in the results of calculating the critical value of the angle of gradient for the tractor with the reversible plough $\mathrm{p} 1$ (degree), obtained by the existing and proposed methods, from the weight of the counterweight with road surfaces of different type

As graphs show, the type of road surface plays a significant role in calculating the critical value of the angle of gradient for the tractor unit. On the given road surfaces the difference can be $4.3^{\circ}$, i.e. the traditional model provides slightly conservative values of the critical angle of gradient for the unit.

\section{Discussion}


The research shows that the most convenient for practical calculations to determine the critical value of the unit angle of gradient is the mathematical model relevant to the third calculation method (formula 20). The values calculated using this model are much more accurate, and the model itself should be considered more successful, since it considers such important parameters as the rolling radius of the tractor rear wheels, the rear wheel tire stiffness, and the characteristics of the road surface.

Taking into account the fact that most of the arable land in Russia is located in mountain areas, it is natural that many scientists have studied the issues of longitudinal stability of tractors and their preservation of the necessary conditions for handling [16-20]. If to compare their approach to the theoretical analysis of the lifting process and the resulting mathematical models, it can be stated that our approach covers a far larger number of factors actually affecting the analyzed process and the assumptions made have a slight effect on the accuracy of calculations, meanwhile allowing to maintain the simplicity of the mathematical model.

\section{Conclusions}

Record of the vertical reactions offset from the vertical axes of symmetry of wheels allows to significantly refine the mathematical model for calculating the critical value of the angle of gradient for the tractor-mounted machine.

\section{References}

1. W. Franco, F. Barbera, L. Bartolucci, T. Felizia, F. Focanti. Development Engineering, 5, 1-14 (2020) https://doi.org/10.1016/j.deveng.2020.100050

2. E. Houshyar, M. Houshyar. Safety Science, 103, 88-93 (2018) https://doi.org/10.1016/j.ssci.2017.11.018

3. M. Ericson. Safety Science, 48(5), 537-543 (2010)

4. G. R. Narasimhana, Y. Penga, T. G. Crowec, L. Hagel, J. Dosmand, W. Pickett, Accident Analysis and Prevention, 42, 1226-1231 (2010)

5. A. B. Kudzaev, T. A. Urtaev, A. E. Tsgoev, I. A. Korobeynik, D. V. Tsgoev, International Journal of Mechanical Engineering and Technology (IJMET), 8(11), 714720 (2017)

6. A. B. Kudzaev, T. A. Urtaev, A. E. Tsgoev, I. A. Korobeynik, D. V. Tsgoev, International Journal of Civil Engineering and Technology (IJCIET), 8(11), 658-666 (2017)

7. A. B. Kudzaev, D. V. Tsgoev, I. A. Korobeynik, T. A. Urtaev, A. E. Tsgoev, International Journal of Civil Engineering and Technology (IJCIET), 9(10), 1421-1429 (2018)

8. A. B. Kudzaev, I. A. Korobeynik, A. E. Tsgoev, D. V. Tsgoev, R. V. Kalagova, T. A. Urtaev, Civil Engineering Journal, 4(12), 3027-3037 (2018)

9. A. B. Kudzaev, A. E. Tsgoev, D. V. Tsgoev, I. A. Korobeynik, R. V. Kalagova, IOP Conf. Series: Earth and Environmental Science, 488 (2020) DOI:10.1088/17551315/488/1/012025

10. J. Sun, C. Meng, Y. Zhang et al., Information Processing in Agriculture, https://doi.org/10.1016/j.inpa.2020.02.004

11. B. Franceschetti, V. Rondelli, A. Ciuffoli. Safety Science, 115, $42-50$ (2019) 
12. K. Rajeev, R. Hifur, Engineering in Agriculture, Enviroment and Food, 8(3), 187-194 (2015)

13. W. Masahisa, S. Kenshi, Biosystems Engineering, 192, 108-116 (2020)

14. L. Zhen, M. Muneshi, O. Takashi, H. Yasumaru, Biosystems Engineering, 134, 55-67 (2015)

15. W. Masahisa, S. Kenshi, Biosystems Engineering, 182, 84-94 (2019)

16. E. V. Priporov, Increase in the longitudinal stability of mounted units. Innovations in agriculture, 5(15), 115-119 (2015)

17. S. N. Kartokhin, E. V. Priporov, Analysis of factors affecting the longitudinal stability of tractors. Vestnik of Kazan State Agrarian University 10, 2(36), 79-81 (2015)

18. D. V. Yurchenko, E. V. Priporov, Longitudinal stability of mounted units. Vestnik of scientific and technical creativity of youth of Kuban State Agrarian University, 137139 (2016)

19. V. R. Romanov, Ballasting of wheeled tractors for working with mounted machines. In the collection: Innovative trends for the development of Russian science. Materials of the IXth International scientific-practical conference of young scientists. Krasnoyarsk, 193-196 (2016)

20. A. V. Skrypnikov, A. A. Tursunov, E. V. Kondrashova, T. V. Skvortsova, M. N. Leonova, Methodology to evaluate the Stability of wheeled and tracked vehicles. Bulletin of Tajik Technical University, 3(23), 82-88 (2013) 